\title{
Koselleck, a história dos conceitos e as temporalidades
}

\section{Koselleck, The History of Concepts and the Temporalities}

\author{
Jose D’Assunçao ${ }^{1}$ \\ Universidade Federal Rural do Rio de Janeiro (Brasil)
}

Recibido: 04-03-15

Aprobado: 13-11-15

\section{Resumo}

Este artigo tem por objetivo examinar, de um ponto de vista historiográfico e da teoria da história, algumas das mais importantes contribuições do historiador alemão Reinhart Koselleck. De um lado, procuraremos delinear a História dos Conceitos como um campo histórico particularmente importante nas últimas décadas. De outro lado, examinaremos as considerações de Reinhart Koselleck, co-fundador do novo campo, no que se refere aos estudos em torno de um conceito específico: o Tempo. A referência principal é o ensaio Futuro Passado, escrito por Koselleck em 1979 -um ensaio no qual este historiador alemão sistematiza suas principais considerações sobre as três instâncias da temporalidade- Passado, Presente e Futuro -utilizando os conceitos de "espaço de experiência" e "horizonte de expectativa".

Palavras-chave: Presente, Passado, Koselleck, História dos Conceitos.

\begin{abstract}
This article aims to examine, in a historiographical view and according the perspective of the Theory of History some of the most important contributions

\footnotetext{
${ }^{1}$ (jose.d.assun@globomail.com). Professor e investigador da Universidade Federal Rural do Rio de Janeiro (Brasil), e professor-colaborador do Programa de Pós-Graduação em História Comparada da Universidade Federal do Rio de Janeiro (Brasil). Suas investigações versam sobre temas ligados à Teoria da História, Historiografia, História das Ciências e História das Artes. Entre suas obras mais destacadas, constam: O Campo da História (2004), Teoria da História - em cinco volumes (2011), O Tempo dos Historiadores (2013), História Comparada (2014).
} 
of the german historian Reinhart Koselleck. On the one hand, we will seek to delineate the History of Concepts as a historical field particularly important in recent decades. On the other hand, we will examine the considerations of Reinhart Koselleck, co-founder of the new field, concerning his studies around a specific concept: Time. The primary reference is the book Future Past, written by Koselleck in 1979-an essay in which one the german historian establish his main considerations about the three levels of temporality- Past, Present and Future -using the concepts of "experience space" and "horizon of expectation".

Key-words: Present, Past, Koselleck, Conceptual History

\section{Introdução}

Neste artigo, pretendemos discutir algumas das contribuições historiográficas de um dos mais importantes historiadores das décadas recentes, falecido em 2006: Reinhart Koselleck. Concentraremos o debate sobre as contribuições de Koselleck a partir do delineamento de uma nova modalidade historiográfica à qual dificilmente se pode deixar de associar o nome deste historiador alemão -a História dos Conceitos- discutindo, em seguida, outra de suas contribuições fundamentais, que foi a reflexão sistemática sobre os problemas históricos e historiográficos relacionados ao tempo. Começaremos com a compreensão em torno deste novo campo histórico que, nos dias de hoje, já possui uma produção bastante diversificada.

\section{História dos Conceitos}

A 'História dos Conceitos' -esta que é uma das modalidades historiográficas mais cotejadas da última década- situa-se em uma confluência particularmente rica de campos históricos.Em última instância, ao menos de acordo com a abordagem proposta por Koselleck, a História dos Conceitos implica em "construir uma relação entre a história das idéias e a história social como um campo de tensões" (Chignola, 2007, p.52). Reinhart Koselleck, além de "historiador dos conceitos", é "historiador da modernidade" (e, mais especificamente, da "segunda modernidade", que seria aquela que se estabelece a partir do limiar que aflora em fins do século XVIII). Por isto, tal como observa Sandro Chignola em sua síntese sobre a perspectiva de história conceitual desenvolvida por Koselleck, almeja "restituir a complexa trama de acontecimentos que torna possível o uso lingüístico contemporâneo" (2007, 
p.53). Uma parcela importante do trabalho de Koselleck é dedicada a este recorte mais específico de estudos. O que estará nos interessando aqui, todavia, é a contribuição mais específica de Koselleck para a Teoria da História.

Abordar os conceitos na História e no decurso da história implica questões particularmente importantes para a historiografia contemporânea. Conceitos existem na própria história (ou seja, expressos nas fontes históricas examinadas pelo historiador), e também na História (historiografia) que vai sendo construída pelo historiador à medida que ele entretece suas reflexões sobre a "história vivida" que lhe chega através dos vestígios do Passado. Dessa maneira, seria possível, ao historiador o considerar dois níveis de conceitos - dois planos através dos quais ele se movimenta em sua prática historiográfica: o plano das suas próprias reflexões e construções historiográficas, e o plano histórico que está sendo examinado:

\begin{abstract}
Quando o historiador mergulha no passado, ultrapassando suas próprias vivências e recordações, conduzido por perguntas, mas também por desejos e inquietudes, ele se confronta primeiramente com vestígios que se conservaram até hoje, e que em maior ou menor número chegaram até nós. Ao transformar esses vestígios em fontes que dão testemunho da história que deseja apreender, o historiador sempre se movimenta em dois planos. Ou ele analisa fatos que já foram anteriormente articulados na linguagem ou então, com a ajuda de hipóteses e métodos, reconstrói fatos que ainda não chegaram a ser articulados, mas que ele revela a partir desses vestígios. No primeiro caso, os conceitos tradicionais da linguagem das fontes servem-lhe de acesso heurístico para compreender a realidade passada. No segundo, o historiador serve-se de conceitos formados e definidos posteriormente, isto é, de categorias científicas que são empregadas sem que sua existência nas fontes possa ser provada (Koselleck, 2006, p.305).
\end{abstract}

Os historiadores lidam ao mesmo tempo com os conceitos ou expressões que uma época passada elaborou para refletir sobre si mesma (e também sobre outras épocas), e com conceitos e categorias decorrentes de sua própria atividade científica como produtores de conhecimento historiográfico sejam estes conceitos criados por eles mesmos ou por uma tradição que já está estabelecida na comunidade dos historiadores. Em decorrência do que foi dito, a História Conceitual apresenta um duplo interesse, pois permite examinar a história (campo de processos e acontecimentos) e a própria História (conjunto de trabalhos e sistema de representações que examinam a história, no sentido anterior). Perceber os conceitos e suas metamorfoses como fenômenos que retratam e se tensionam contra a sociedade e que -se de um lado, elevam-se do fundo da história e da vida, por outro lado terminam por contribuir para redefini-la e por redirecioná-la- é um primeiro campo de análises ${ }^{2}$. Os conceitos, como objetos e sujeitos da história, permitem também

\footnotetext{
${ }^{2}$ Koselleck chamou atenção para este potencial dos conceitos para transformar a história, isto
} 
que se redefina essa tradicional relação entre objetividade e subjetividade. Entrementes, é possível ainda dirigir o olhar da História Conceitual para a própria Historiografia: dar a perceber como, através dos conceitos, vai se transformando a própria escrita da História. Há por fim, a possibilidade de examinar as discordâncias e convergências entre a História e a história. Isto porque, tal como ressalta o próprio Koselleck, "a história dos conceitos mede e estuda essa diferença e convergência entre os conceitos antigos e as atuais categorias de conhecimento" (2006, p.306).

\section{O estudo do Tempo Histórico}

Para além de uma História dos Conceitos propriamente dita - isto é, a história dos diversos significados e apropriações de conceitos em determinada sociedade, sem mencionar a já comentada possibilidade de examinar a própria história de uma sociedade através do surgimento e modificações dos conceitos um estudo particularmente importante do Conceitual é aquele que visa examinar as diferentes recepções e sensibilidades diante de certos conceitos. Talvez o exemplo mais emblemático que Koselleck nos ofereceu desta modalidade da História dos Conceitos foi o seu já clássico estudo sobre o Tempo e as diversas instâncias da Temporalidade.

O esforço de compreender o tempo em suas múltiplas facetas, históricas e historiográficas, foi de fato um ostinato na produção intelectual de Reinhart Koselleck. O historiador alemão desenvolveu uma singular perspectiva sobre o Tempo que chama atenção para o fato de que cada Presente não apenas reconstrói o Passado a partir de problematizações geradas na sua atualidade -tal como, aliás, já propunham os Annales e outras correntes do século $\mathrm{XX}$ - mas também de que cada Presente ressignifica tanto o Passado (referido na conceituação de Koselleck como "campo da experiência") como o Futuro (referido conceitualmente como "horizonte de expectativas"). Mais ainda, cada Presente concebe também de uma nova maneira a relação entre Futuro e Passado, ou seja, a assimetria entre estas duas instâncias da temporalidade, e não é por acaso que o título de sua

\footnotetext{
é, "criar experiência", em um de seus ensaios. Se os conceitos podem ser produtos de realidades históricas concretas, por outro lado há conceitos que, eles mesmos, criam novas realidades históricas. Nestes casos, "já não se trata mais de conceitos que classificam experiências, mas de conceitos que criam experiências" (Koselleck, 2006, p.324). O historiador alemão, ainda neste mesmo ensaio, dá o exemplo do conceito de "republicanismo", criado por Kant na obra Paz Perpétua (1795) para expressar um "movimento" que se impulsiona em direção à República (2006, p.69). O conceito, tal como indica Koselleck, "servia para antecipar teoricamente o movimento histórico e influenciá-lo praticamente" (p.325). Logo depois, no século XIX e mais além, no século XX, surgiriam outros "conceitos de movimento" (o que, para Koselleck, já constitui, aliás, um traço da modernidade). "Socialismo", "democratismo", "liberalismo", "comunismo", "fascismos" - eis aqui uma série de conceitos que passam a "influir diretamente no acontecer político" (p.325).
} 
mais conhecida coletânea de ensaios é Futuro Passado - contribuição à semântica dos tempos históricos (1979).

Constitui a contribuição mais notável de Koselleck para a Teoria da História a apurada percepção desta tensão que sempre se estabelece entre o 'espaço de experiência' e o 'horizonte de expectativas', uma tensão própria da elaboração do conhecimento historiográfico e mesmo das múltiplas leituras sobre o fenômeno da temporalidade que vão surgindo em cada época, inclusive ao nível das pessoas comuns que vivenciam os padrões disponíveis de sensibilidade diante do tempo que lhes são oferecidos no momento em que vivem.

Para Koselleck, assim como para outros historiadores e filósofos que refletiram mais recentemente sobre o Tempo, são construções essencialmente humanas -coletivas e individuais- as sensações acerca do tempo, da passagem do tempo, do ritmo de aceleração ou desaceleração do tempo, bem como as concepções sobre o Passado, o Presente, o Futuro, e também sobre as relações entre estas instâncias da temporalidade. Não é desconhecida de ninguém a percepção, através de nossa própria vida individual, de que as sensações diante do tempo mudam nas diversas fases da vida humana que chamamos de "infância", "adolescência", "maturidade", "velhice" ("terceira idade"). Em uma e outra destas fases, o tempo parece se acelerar (sensações que, ademais, são interferidas pela própria experiência específica de cada um, ou pelas circunstâncias que afetam cada vida em cada período). De igual maneira, as relações temporais e as ressignificações do Passado e do Futuro também constituem construções coletivas, que se superpõem às experiências individuais.

Um exemplo interessante é-nos lembrado por Hannah Arendt, autora que podemos cotejar com Koselleck, uma vez que também se interessou em alguns ensaios pelas relações entre as temporalidades. Afilósofa nos mostra como, entre os antigos romanos (e distintamente dos gregos), o Passado passa a adquirir o peso de uma autoridade. Os acontecimentos do passado, para os antigos romanos, remetiam a exemplos a serem reverenciados e também a momentos de uma história que remontava no seu instante mais remoto à "Fundação de Roma" - o grande evento politicamente sacralizado e que trazia todos os sentidos possíveis para a grandeza romana. Entre os romanos, o passado deixa de ter a leveza de um ensinamento e a urgência de uma preservação da memória (como entre os gregos) e passa a adquirir o peso de uma autoridade que deve interferir no mundo dos vivos. Através da Tradição, o Presente precisa ser diuturnamente "religado" a este Passado que se acha sacralizado por um grande momento fundador, estabelecendo-se então uma religio ${ }^{3}$. Concomitantemente,

\footnotetext{
3 Para os romanos, o momento fundador, que justifica e impõe sua autoridade sobre todos os outros, foi a Fundação de Roma (e é somente por isso que ela é chamada de "a cidade eterna"). Para os cristãos, que retomam aos romanos pagãos a tríade que une Autoridade, Tradição e Religio, o grande momento fundador é a morte e ressurreição de Cristo. Tanto para os romanos antigos, como 
nesse ambiente mental em que o Passado sacraliza-se e adquire autoridade sobre os vivos, o homem "idoso" passava a adquirir um novo significado, como faz notar Hannah Arendt:

Eis porque a idade provecta, distintamente da simples maturidade, continha para os romanos o próprio clímax da vida humana; não tanto pela sabedoria e experiência acumuladas, como porque o homem velho crescera mais próximo aos antepassados e ao passado. Ao contrário do nosso conceito de crescimento, em que se cresce para o futuro, para os romanos o crescimento dirigia-se no sentido do passado. Se se quiser relacionar esta atitude com a ordem hierárquica estabelecida pela autoridade, visualizando essa hierarquia na familiar imagem da pirâmide, é como se o cimo da pirâmide não se estendesse até às alturas de um céu acima (ou, como no Cristianismo, além) da terra, mas nas profundezas do passado terreno (Arendt, 2009, p.166) ${ }^{4}$.

As civilizações, e as diversas sociedades em momentos distintos de sua história, reconstroem as suas diversas formas de perceber, apreender, compreender, sentir e ressignificar o tempo. Examinemos o sistema desenvolvido por Koselleck para dar suporte à sua teoria sobre a percepção do tempo.

\section{Experiência e Expectativa}

O historiador alemão delineia dois conceitos para a compreensão da sensibilidade humana diante do tempo. "Experiência" e "expectativa" são apresentadas por Koselleck como duas categorias históricas (duas categorias para uso da Teoria da História, melhor dizendo) que "entrelaçam passado e futuro" (Koselleck, 2006, p.308). Através das diversas formas de relação entre as categorias da experiência e da expectativa, Koselleck procura mostrar que cada uma das temporalidades -o Passado, o Presente e o Futuro- pode imaginariamente se alterar, contrair ou se expandir, o que ocorre em cada época ou sociedade, modificando-se neste caso também a maneira como são pensadas e sentidas as relações entre eles ${ }^{5}$.

A escolha específica destas duas expressões -“espaço de experiência” para representar o Passado, e "horizonte de expectativas" para representar o Futuro-

para a Igreja Católica dos períodos históricos subseqüentes, a existência de um momento fundador, bem situado no tempo, torna-se primordial. Nos tempos contemporâneos, conforme veremos até o final deste artigo, esta religio - "religação com o Passado"- mostra-se rompida na percepção mais corrente do tempo.

${ }^{4}$ Os comentários de Hannah Arendt a respeito encontram-se no seu ensaio "O que é a Autoridade" (1957), republicado na coletânea Entre o Passado e o Futuro (2009, p.127-187).

5 "O tempo histórico não apenas é uma palavra sem conteúdo, mas uma grandeza que se modifica com a história, e cuja modificação pode ser deduzida da coordenação variável entre experiência e expectativa" (Koselleck, 2006, p.309). 
não é gratuita. A experiência pertence ao Passado que se concretiza no Presente de múltiplas maneiras: através da memória, dos vestígios, das permanências e, para os historiadores, das fontes históricas. Talvez não haja definição mais precisa do que aquela que é trazida pelo próprio Koselleck:

A experiência é o passado atual, aquele no qual acontecimentos foram incorporados e podem ser lembrados. Na experiência se fundem tanto a elaboração racional quanto as formas inconscientes de comportamento, que não estão mais, que não precisam estar mais presentes no conhecimento. Além disso, na experiência de cada um, transmitida por gerações e instituições, sempre está contida e é preservada uma experiência alheia. Neste sentido, também a história é desde sempre concebida como conhecimento de experiências alheias (Koselleck, 2006, p.309-310).

Já as expectativas - que visam ao Futuro -correspondem a todo um universo de sensações e antecipações que se referem ao que ainda virá. Nossos medos e esperanças, ansiedades e desejos, apatias e certezas, inquietudes e confianças tudo o que aponta para o futuro através das nossas expectativas- fazem parte deste "horizonte de expectativas". As expectativas, além disso, não apenas são constituídas pelas formas de sensibilidade com relação ao futuro que se aproxima, mas também pela curiosidade a seu respeito e pela análise racional que o aborda. A expectativa, enfim, é tudo aquilo que hoje (ou em um determinado Presente) mira o Futuro, crivando-o das sensações as mais diversas. É por isto que Koselleck lembra que, tal como a experiência (esta herança do passado) se realiza no Presente, "também a expectativa se realiza no hoje", constituindo-se, portanto, em um futuro presente.

Embora a experiência associe-se comumente ao Passado Presente, e a expectativa ao Futuro Presente, é importante atentar para a já mencionada afirmação de Koselleck de que estas duas categorias "entrelaçam o Futuro e o Passado". Elas não se opõem uma à outra, como em uma dicotomia qualquer; e de fato "experiência" e "expectativa" estão sempre prontas a repercutir uma sobre a outra, São categorias complementares, visto que a experiência abre espaços para um certo horizonte de expectativas. Mais ainda, uma experiência ou o 'registro de uma experiência' referido a um passado remoto pode produzir, em outra época, expectativas relacionadas ao futuro. Koselleck, no texto mais elucidativo acerca desse sistema conceitual, fornece um exemplo extraído da própria história conhecida. O exemplo é autoesclarecedor:

Podemos citar um exemplo simples: a experiência da execução de Carlos I abriu, mais de um século depois, o horizonte de expectativas de Turgot, quando ele insistiu com Luís XVI que realizasse as reformas que o haveriam de preservar de um destino semelhante. $\mathrm{O}$ alerta de Turgot ao rei não encontrou eco. Mas entre a Revolução Inglesa Passada e a Revolução Francesa futura foi possível descobrir e experimentar uma relação temporal que ia além da mera cronologia. A história concreta amadurece em meio a determinadas experiências e determinadas expectativas (Koselleck, 2006, p.308-309). 


\section{Espaço e Horizonte}

Outro aspecto particularmente interessante relaciona-se aos dois conceitos que se colocam, respectivamente, junto a "experiência" e "expectativa". Tentemos compreender porque um "espaço de experiência" e um "horizonte de expectativas". A partir dos conceitos fundamentais de Koselleck, vamos construir uma possibilidade de explicação e entendimento de como funcionam as imagens d o "espaço" e do "horizonte" nestas duas noções desenvolvidas por Koselleck para favorecer uma compreensão mais complexa acerca das temporalidades.

"Horizonte de Expectativa"

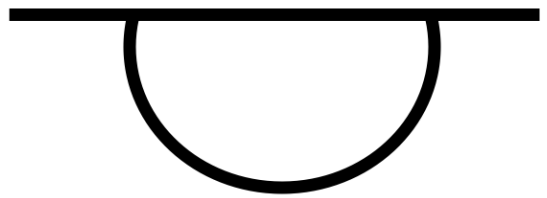

"Espaço de Experiência"

O "Passado Presente" pode melhor ser representado como um espaço porque concentra um enorme conjunto de coisas já conhecidas. Pensemos na figura acima como uma possibilidade de representação. Ela é composta de uma linha horizontal, que representará o horizonte de expectativas, e de um semicírculo colado a esta, que representará o campo de experiências. Existe uma infinita região do Passado que não é conhecida, e que, na verdade, jamais será conhecida Podemos entender este Passado incognoscível, do qual jamais saberemos nada a respeito, como estando fora do semicírculo. Aquilo que não deixou memória, ou cujas memórias já pereceram; aquilo que não deixou vestígios, nem fontes para os historiadores; aquilo que não está materializado no presente a partir das permanências, das continuidades, da língua, dos rituais ainda praticados, dos hábitos adquiridos, tudo isto faz parte de uma experiência perdida, que se situa fora do semicírculo. O que está dentro do semicírculo, contudo, corresponde ao "espaço de experiência". Tudo o que ficou do que um dia foi vivido, e se projeta hoje no presente de alguma maneira, está concentrado neste espaço que é fundamental para a vida, e particularmente vital para os historiadores - pois estes só podem acessar o que foi um dia vivido através desse espaço configurado por experiências que se aglomeram sob formas diversas, e dos quais os historiadores extraem as suas fontes históricas. Tal como esclarece Koselleck, a experiência elabora acontecimentos passados e tem o poder de torná-los presentes, e neste sentido está "saturada de realidade" (2006, p.312) .

${ }^{6}$ Reinhart Koselleck assim justifica sua escolha da metáfora espacial para o campo da "experiência": "Tem sentido se dizer que a experiência proveniente do passado é espacial, porque ela se aglomera para formar um todo em que muitos estratos de tempos anteriores estão simultaneamente presentes, sem que haja referência a um antes e um depois" (Koselleck, 2006, p.311). 
Pode-se pensar ainda na transferência de elementos do "campo de experiência" para aquele espaço indefinido do passado que já se torna inacessível. Memórias podem se perder, fontes podem se deteriorar e se tornarem ilegíveis, arquivos podem se incendiar, rituais podem deixar de serem praticados e tradições podem passar a não mais serem cultivadas. Quando morre um indivíduo, certamente o mundo perde para este espaço exterior algo do que poderia ser conhecido, do que estava efemeramente situado dentro do semicírculo e que jamais poderá ser recuperado. A História Oral, uma modalidade mais recente das ciências históricas, é por esse motivo uma conquista extremamente importante para a historiografia, e mesmo para a humanidade. Através dessa abordagem histórica, é possível fixar de algum modo o que um dia iria se perder, pois as memórias podem ser registradas em depoimentos, gravados ou anotados, e as visões e percepções de mundo de indivíduos que um dia irão perecer também podem encontrar o seu registro. É possível imaginar que algo que também parecia estar no espaço exterior também venha um dia para dentro do semicírculo, nos momentos em que os historiadores descobrem novas fontes, ou mesmo novas técnicas para extrair de fontes já conhecidas elementos que antes não pareciam fazer parte do "espaço de experiência".

Qualquer Passado, qualquer coisa que hoje está no interior desse semicírculo que é o "espaço de experiência" ou o "Passado Presente", assim como ainda aquilo o que se perdeu para fora dele mas que, não obstante, um dia foi vivido, já correspondeu outrora a um Presente. Nosso presente, cada instante que vivenciamos, logo se tornará um passado, e mesmo ocorrendo com o futuro que ainda não conhecemos. Por isso mesmo, a cada segundo, a cada novo presente, o espaço de experiência se transforma. $\mathrm{O}$ que podemos acessar de um vivido e de uma experiência que nos chega do passado revolve-se constantemente, reapresentando-se a cada vez de uma nova maneira ${ }^{7}$. As próprias experiências já adquiridas podem se modificar com o tempo, e Koselleck oferece o exemplo dos acontecimentos relativos à ascensão do Nazismo, entre os quais o criminoso incêndio do Parlamento Alemão. "Os eventos de 1933 aconteceram de uma vez por todas, mas as experiências baseadas neles podem mudar com o correr do tempo; as experiências se superpõem, impregnam-se umas das outras" (Koselleck, 2006, p.312-313) ${ }^{8}$.

Quanto ao "Futuro Presente" o Futuro que ainda não ocorreu, mas cuja proximidade ou distância repercute no Presente sob a forma das mais diversas expectativas -este é representável por uma linha. Na verdade, é representado por uma linha porque é efetivamente o que está para além desta

\footnotetext{
7 Em Futuro Passado (1979), no ensaio em que discute os conceitos de "espaço de experiência" e "horizonte de expectativas", Koselleck toma emprestada uma imagem de Christian Metz: "o olho mágico de uma máquina de lavar, atrás do qual de vez em quando aparece esta ou aquela peça colorida de toda a roupa que está contida na cuba" (Koselleck, 2006, p.311).

8 Koselleck ainda acrescenta: "E mais: novas esperanças ou decepções retroagem, novas expectativas abrem brechas e repercutem nelas. Eis a estrutura temporal da experiência, que não pode ser reunida sem uma expectativa retroativa" (2006, p.313).
} 
linha, correspondendo àquilo que ainda não é conhecido. Temos apenas uma "expectativa" sobre o futuro, mas efetivamente não podemos dizer como ele será. Por isso aplica-se aqui a metáfora do horizonte -o extremo limite que se oferece à visão, e para além do qual sabemos que há algo, mas não sabemos exatamente o que é. Sempre que nos aproximamos do horizonte, ele recua, de modo que nunca deixará de persistir como uma linha além da qual paira o desconhecido, que logo se tornará conhecido porque se converterá em presente. Conforme as próprias palavras de Koselleck, "horizonte quer dizer aquela linha por trás da qual se abre no futuro um novo espaço de experiência, mas um espaço que ainda não pode ser contemplado; a possibilidade de se descobrir o futuro, embora os prognósticos sejam possíveis, se depara com um limite absoluto, pois ela não pode ser experimentada" (Koselleck, 2006, p.311).

Entre estas duas imagens se comprime o Presente: um fugidio momento de difícil representação visual que parece se comprimir entre o espaço concentrado que representa o Passado (antes de logo se incorporar a ele) e a linha fugidia que representa o Futuro - esta linha eternamente móvel, pois rapidamente o que ele traz, tão logo se torne conhecido, transforma-se por um segundo em Presente e logo depois passa a ser englobado pelo interior do semicírculo que corresponde ao "espaço de experiência" (quando não se perde no Passado incognoscível situado fora do semicírculo).

\section{Assimetria entre Passado-Presente e Futuro-Presente}

É importante ressaltar que o "Passado Presente" e o "Futuro Presente", ou o "campo de experiências" e o "horizonte de expectativas", não constituem conceitos simétricos -ou "imagens especulares recíprocas" tal como alerta Koselleck (2006, p.310). Imaginariamente, o campo de experiência, o Presente, e o horizonte de expectativas podem produzir as relações mais diversas, e assim ocorre no decorrer da própria história. Há épocas em que o tempo parece aos seus contemporâneos se desenrolar lentamente, e outras em que parece estar acelerado, em função da rapidez das transformações políticas ou tecnológicas ${ }^{9}$. Existem períodos da história, crivados de movimentos revolucionários,

9 "O que antes marchava passo a passo, agora vai a galope", dizia o escritor nacionalista e poeta Ernst Moritz Arndt (1769-1860) em 1807 (Koselleck, 2006, p.289). De igual maneira, inúmeros autores do século XIX, investigados por Koselleck, parecem se manifestar acerca desta nova sensação de aceleração temporal que é típica da modernidade, tal como o poeta e historiador Alphonse de Lamartine (1790-1869), na seguinte passagem de História da Restauração (1851): "Não há mais história contemporânea; os dias de ontem já parecem estar sepultados bem fundo nas sombras do passado" (Lamartine, 1851, p.1). É também este o caso do historiador alemão Georg Gottfried Gervinus (1805-1871), que em sua Introdução à História do século XIX (1853, p.174) observava que os movimentos do século XIX "sucedem-se no tempo quase em progressão geométrica". Sobre isto, ver outro ensaio de Koselleck, intitulado "Modernidade", incluído em Futuro Passado (2006, p.267-303).

Araucaria. Revista Iberoamericana de Filosofia, Política y Humanidades, año 18, nº 35. Primer semestre de 2016. Pp. 41-53. ISSN 1575-6823 e-ISSN 2340-2199 doi: 10.12795/araucaria.2016.i35.03 
nos quais os agentes que deles participam desenvolvem a sensação de que o futuro é aqui agora, tendo se fundido ao presente. Em outros, inclusive, o futuro parece permanecer "atrelado ao passado", tal como naqueles em que as expectativas do futuro não se referem a este mundo, mas sim a um outro que será escatologicamente trazido pela redenção dos tempos ${ }^{10}$. As fusões e clivagens que se estabelecem imaginariamente entre as três temporalidades Passado, Presente e Futuro - podem aparecer ao ambiente mental predominante em cada época, e às consciências daqueles que vivem nestas várias épocas, de maneiras bem diferenciadas.

Para Koselleck, o tempo histórico é ditado, de forma sempre diferente, pela tensão entre expectativas e experiência (2006, p.313). Há por exemplo ações e práticas humanas que são constituídas precisamente dessa tensão, tal como ocorre com a elaboração de "prognósticos", que sempre exprimem uma expectativa a partir de um certo campo de experiências (portanto, a partir de um "diagnóstico"). Disse-nos também o historiador alemão que "o que estende o horizonte de expectativa é o espaço de experiência aberto para o futuro", o que se pode dar de múltiplas maneiras, conforme a relação estabelecida entre as duas instâncias (2006, p.313). Como se disse, em cada época pode haver uma tendência distinta a reavaliar a tensão entre o espaço de experiência e o horizonte de expectativas (ou entre o Passado e o Futuro, através da mediação do Presente). Apenas para ilustrar com uma das hipóteses de Koselleck, na modernidade "as expectativas passam a distanciar-se cada vez mais das experiências feitas até então" (2006, p.314); em contrapartida, em todo o ambiente mental predominante no ocidente até meados do século XVII, o futuro parecia permanecer fortemente atrelado ao próprio passado $\left(2006\right.$, p.315) ${ }^{11}$. Poderíamos mesmo pensar em duas representações para os dois momentos da história das sensibilidades europeias em relação ao Tempo, já que, no período propriamente moderno, “o espaço de experiência deixa de estar limitado pelo horizonte de expectativa; os limites de um e de outro se separam" (Koselleck, 2006, p.318) ${ }^{12}$ :

${ }^{10}$ Koselleck dá o exemplo de um dos períodos da história europeia anterior à segunda metade do século XVII, no qual "a doutrina cristã dos últimos dias impunha limites intransponíveis ao horizonte de expectativa". Neste caso, continua o historiador alemão, "a revelação bíblica, gerenciada pela igreja, envolvia de tal forma a tensão entre experiência e expectativa que elas não podiam separar-se" (Koselleck, 2006, p.315).

${ }^{11}$ Isso não quer dizer, obviamente, que não haja diferenças entre os grupos sociais e ambientes diversos com relação aos modos de perceber o tempo e de vivenciar as relações entre o "espaço de experiências" e o "horizonte de expectativas". Koselleck admite que "esta constatação, de uma transição quase perfeita das experiências passadas para as expectativas vindouras, não pode ser aplicada de igual maneira a todas as camadas sociais" (Koselleck, 2006, p.315).

${ }_{12}$ Koselleck procura traçar o esboço histórico dos elementos que presidem esta mudança nas relações entre "espaço de experiências" e "campo de expectativas", que começa a se explicitar na segunda metade do século XVII e se acentua no decorrer do século XVIII. Três dos principais elementos aqui presentes serão a nova noção de Progresso, a ocorrência de inovações tecnológicas em ritmo mais rápido, e a conseqüente sensação de "aceleração do ritmo temporal". Sobre o desenvolvimento do conceito de Progresso. Koselleck procura mostrar como se torna cada vez mais recorrente a ideia de 


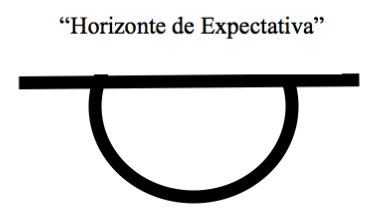

"Espaço de Experiência"
"Horizonte de Expectativa"

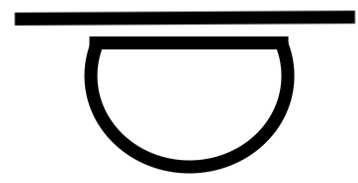

"Espaço de Experiência"

Figura: Duas representações: as relações entre "espaço de experiência" e "horizonte de expectativas" antes e depois de 1750

As possibilidades de refletir de forma mais sistemática sobre as relações entre as três temporalidades, enfim, enriqueceram-se consideravelmente com as proposições de Reinhart Koselleck, particularmente com a aplicação dos conceitos de "campo de experiências" e "horizonte de expectativas". Com este sistema para a compreensão do tempo e de sua recepção, e com a consolidação desta nova modalidade historiográfica que é a História dos Conceitos, o historiador alemão, falecido em 2006 deixava um legado de grande importância para a comunidade historiográfica.

que "o futuro será diferente do passado, vale dizer, melhor". A produção intelectual de filósofos como Kant (1784) estará a partir daí a serviço desta nova ideia de um futuro melhor, e que não pode ser previsto apenas "olhando para o passado" com base na ideia de que o mesmo sempre retorna, tal como ocorria com a velha ideia de uma História “mestra da vida" em Maquiavel (1512). "O 'progresso' é o primeiro conceito genuinamente histórico que apreendeu em um conceito único, a diferença temporal entre experiência e expectativa" (Koselleck, 2006, p.320). 


\section{Referências}

Arendt, Hannah, "A Quebra entre o Passado e o Futuro" in: Entre o Passado e o Futuro, Perspectiva, São Paulo, 2009, p.28-42 [original: 1954].

Arendt, Hannah, "A Tradição e a Época Moderna" in: Entre o Passado e o Futuro, Perspectiva, São Paulo, 2009, p.43-68 [original: 1956].

Barros, José D’Assunção, O Campo da História, Editora Vozes, Petrópolis, 2004.

Barros, José D’Assunção, Teoria da História- em cinco volumes, Editora Vozes, Petrópolis, 2011.

Barros, José D'Assunção, O Tempo dos Historiadores, Editora Vozes, Petrópolis, 2013.

Barros, José D’Assunção, História Comparada, Editora Vozes, Petrópolis, 2014.

Chignola, Sandro, "História dos Conceitos e História da Filosofia Política" in Jasmin, Marcelo e Feres Jr., João (orgs.), História dos Conceitos diálogos transatlânticos, PUC, Rio de Janeiro, 2007, p.45-57.

Gervinus, Georg Gottfried, Einleitung in die Geschichte des neunzehnten Jahrhunderts [Introdução à História do século XIX], Erler, Leipzig, 1853.

Kant, Immanuel, Ideia de uma História Universal de um Ponto de Vista Cosmopolita, Brasiliense, São Paulo, 1986 [original: 1784].

Koselleck, Reinhart, "Modernidade" in: Futuro Passado - contribuição à semântica dos tempos históricos, Contraponto, Rio de Janeiro, 2006, p.267-303.

Koselleck, Reinhart, "Espaço de experiência e horizonte de expectativas" in: Futuro Passado - contribuição à semântica dos tempos históricos, Contraponto, Rio de Janeiro, 2006, p.311-337 [original: 1979].

Lamartine, Alphonse de, Histoire de La Restauration, Pagnerre, Lecou, Furne e co. Paris, 1851.

Maquiavel, Nicolau, Discursos sobre a Primeira Década de Tito Livio, Martins Fontes, São Paulo, 2007 [original: 1512-1517].

Tocqueville, Aléxis, Democracy in America. Vintage Books, New York, 1945 [original: 1835]. 
